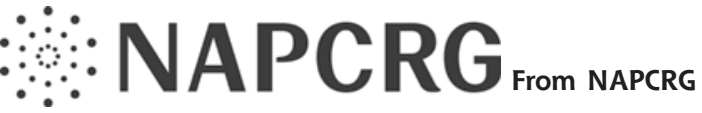

Ann Fam Med 2021;19:373. https://doi.org/10.1370/afm.2723.

\section{NAPCRG ACCEPTING NOMINATIONS FOR THE MAURICE WOOD AWARD FOR LIFETIME CONTRIBUTION TO PRIMARY CARE RESEARCH}

The Maurice Wood Award for Lifetime Contribution to Primary Care Research is given annually to honor a researcher who has made outstanding contributions to primary care research over the course of a lifetime. Scientists from all nations, working in all professional fields and scientific disciplines, are eligible to receive the Wood Award, which is presented at the NAPCRG Annual Meeting, November 19-23 (fully virtual) https://napcrg.org/conferences/annual/annualmeeting/. The award is named in honor of Maurice Wood, a pioneer in primary care research and a founder of NAPCRG.

NAPCRG solicits nominees for the annual Wood Award from members and other professionals. To nominate an individual for the 2021 Wood Award, complete the nomination form at the link below, upload a $\mathrm{CV}$ and a letter describing the nominee's contributions to primary care research and state why the person should be a candidate. Nominations must be received by August 31, 2021.

Past recent recipients include esteemed leaders in the field such as Paul Stephen Little, MD, MSc (2020), William R. Phillips, MD, MPH (2019), Kurt Stange, MD, PhD (2018), and Moira Stewart, PhD (2017).

\section{Nominee Criteria}

- The Nominee can be from any nation, profession, or scientific discipline

- The Nominee should be a primary care or family medicine researcher

- The Nominee must be living at the time of nomination

\section{Selection}

Nominees will be evaluated on:

- Overall body of lifetime work

- Personal research achievements

- Contributions to building primary care research

The Wood Award is supported by donations from friends of primary care research across North America and around the world, including NAPCRG members and the Georgia Health Sciences University's Department of Family Medicine in the Medical College of
Georgia and the Medical College of Georgia Foundation Hames Endowment.

Nominations may be submitted online https://www. napcrg.org/programs/awards/maurice-wood-award/.

If you have questions about the Maurice Wood Award, contact Julie Sutter, via email jsutter@napcrg org

Julie Sutter, NAPCRG Executive Director

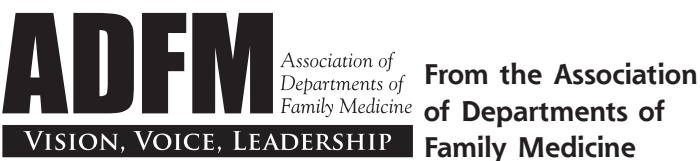

Ann Fam Med 2021;19:373-374. https://doi.org/10.1370/afm.2721

\section{FAMILY MEDICINE EDUCATORS AS EXEMPLARS OF MASTER ADAPTIVE LEARNING IN RESPONSE TO THE COVID-19 PANDEMIC}

"Master adaptive learning" (MAL) refers to the ability to adapt expertise to both routine and uncommon situations - termed adaptive expertise - that has been suggested as a necessary skill for physicians. Beyond the typical Dreyfus model of ranging from novel to expert ${ }_{1}^{1}$ the adaptive expert is able to continue to grow beyond the expertise obtained during training (Figure 1). ${ }^{2}$ When the COVID-19 pandemic imposed restrictions on in-person educational experiences, educators recognized that what worked in the past would no longer work. We required innovative solutions. Fortunately, as family physicians we know that one size never fits all. We exemplify MAL in our daily practice, because we constantly customize our practice to accommodate the complex and shifting needs of individual patients. ${ }^{3}$ During the COVID-19 pandemic, Departments of Family Medicine (DFMs) have demonstrated their MAL skills, bringing flexibility, versatility, and creativity to medical schools to learning options for medical students. ${ }^{4}$ Here we provide 4 specific examples of these innovations.

Morehouse School of Medicine (MSM) realized very early the need to mitigate social isolation/loneliness/inactivity with seniors during the pandemic. The MSM Students Hanging out With Seniors (MSM SHOWS) compassionate care curriculum was developed and implemented in the Department of Family Medicine for medical and physician assistant students. The students were paired with 1 or 2 seniors living in high rises and virtual social check-ins were conducted at least weekly using a video calling app on an iPad. 


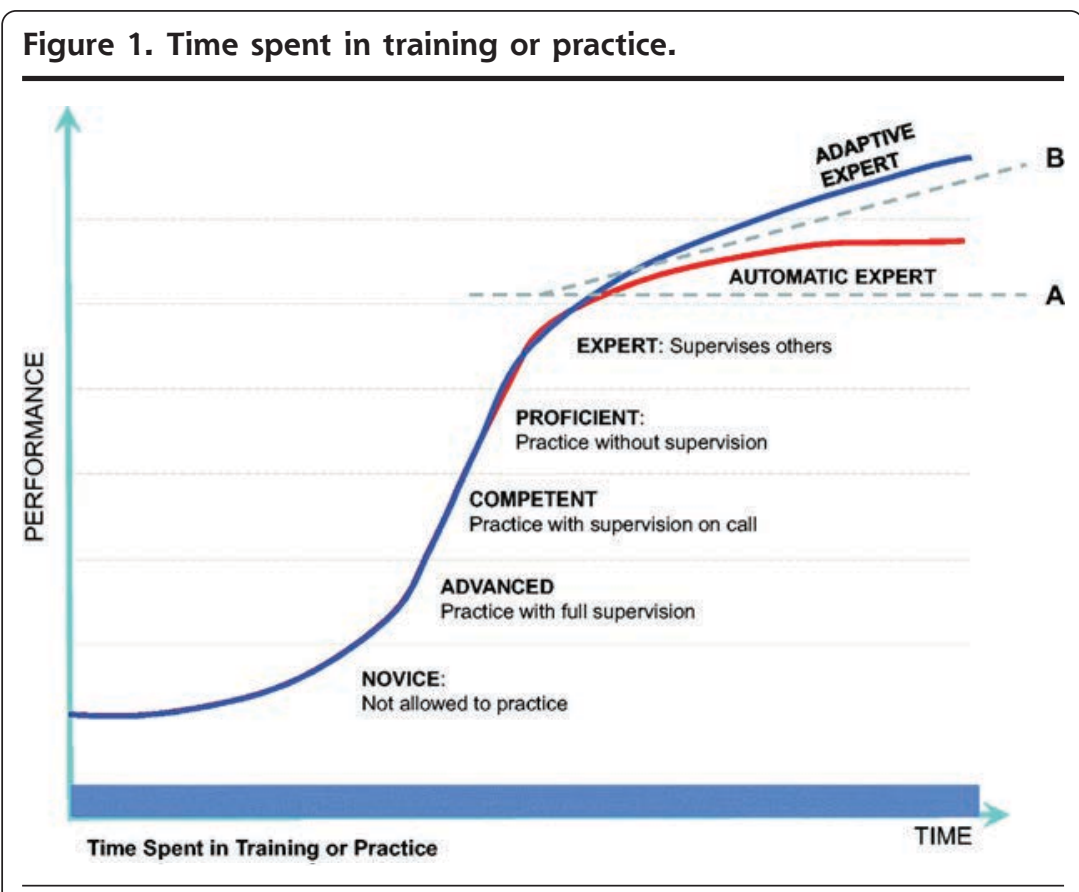

Reprinted with permission from Pusic MV, Santen SA, Dekhtyar M, et al. Learning to balance efficiency and innovation for optimal adaptive expertise. Med Teach. 2018;40(8):820-827.

The University of Texas Southwestern Medical Center experienced considerable concern about decreased student opportunities to participate in clinical decision making. A new casebased elective was developed utilizing readily available resources. Via the university library, all students had access to a text entitled, Symptom to Diagnosis: An Evidence-Based Guide. ${ }^{5}$ Using this text, students presented cases, led Socratic discussions to formulate differential diagnoses, and proposed evaluation plans. Faculty were present, but mainly served as consultants or facilitators.

The broad scope of practice of family physicians helps us to be master adaptive learners, because we are experienced at identifying the limits of our expertise and seeking information that allows us to extend our

The University of South Dakota Sanford School of Medicine DFM recognized the challenge of remotely teaching 1st- and 2nd-year students physical exam skills and allowing for adequate practice. Faculty and staff determined which students were roommates or had other personal connections and assigned those students to practice physical exam skills with each other. Subsequently those skills were tested with each other rather than utilizing standardized patients. These student pairs or cohorts decreased contact between groups of students, patients, and others, thereby decreasing risk of exposure. While this was a relatively easy solution, it was not necessarily initially obvious.

The primary care clerkship director at the University of South Florida's Allentown campus recognized that decreasing quality metrics due to patients' fear of presenting for wellness care represented an opportunity for clerkship students who were unable to be present in person for the clerkship. Third-year students were asked to call patients who had not received recommended screening tests. After contacting the patients, students connected with a preceptor to fill care gaps and in many cases identified new concerns or questions that were addressed virtually in partnership with the preceptor. Using this approach, patients received needed care, students gained experience in population health management, and clinicians connected with their empaneled patients during a time when fear prevented the normal means of that connection. knowledge in response to new questions. As we have described, the application of that ability to our roles as educators ${ }^{6}$ within the context of the COVID-19 pandemic demonstrates this well. We need more research to understand how family physicians develop into master adaptive learners, as well as how we might apply the lessons learned from the pandemic to barriers that arise during education and practice.

$$
\text { Drew Keister, MD, Folashade Omole, MD, FAAFP, }
$$$$
\text { Dan Sepdham, MD, Susan Anderson, MD, FAAFP }
$$

\section{References}

1. Dreyfus SE, Dreyfus HL. Mind Over Machine: The Power of Human Intuition and Expertise In the Era of the Computer. The Free Press; 1986.

2. Pusic MV, Santen SA, Dekhtyar M, et al. Learning to balance efficiency and innovation for optimal adaptive expertise. Med Teach. 2018;40(8):820-827. https://doi.org/10.1080/01421 59X.2018.1485887

3. Cutrer WB, Atkinson HG, Friedman E, et al. Exploring the characteristics and context that allow Master Adaptive Learners to thrive. Med Teach. 2018;40(8):791-796. https://doi.org/10.1080/01421 59X.2018.1484560

4. Everard KM, Schiel KZ. Changes in family medicine clerkship teaching due to the COVID-19 pandemic. Fam Med. 2021;53(4):282-284. https://doi.org/10.22454/FamMed.2021.583240

5. Stern SC, Cifu AS, Altkorn D, eds. Symptom to Diagnosis: An Evidence-Based Guide, 4 Ed. McGraw-Hill; 2019. Accessed May 18, 2021. https://accessmedicine. $m$ mmedical.com/content.aspx?bookid= 2715 \&sectionid $=228237277$

6. Edje LC. Program director as master adaptive learner. Acad Med. 2019;94(9):1263. https://doi.org/10.1097/ACM.0000000000002825 